\title{
GRAMATICALIZACCÃO DO SINAL "MOTIVO" NA LÍNGUA BRASILEIRA DE SINAIS: UMA ANÁLISE BASEADA NO USO
}

\section{Grammaticalization of the "motivo" sign in brazilian sign language: a use-based analysis}

Resumo: O objetivo deste trabalho é apresentar uma análise inédita dos usos do sinal motivo na Língua Brasileira de Sinais, glosado frequentemente como "por isso" ou "por causa", buscando oferecer evidências do seu uso polissêmico e multifuncional. Nossa hipótese é a de que os diferentes usos de MOTIvo representam diferentes estágios de gramaticalização (HOPPER; TRAUGOTT, 2003), em que um mesmo sinal é usado como nome, advérbio e conjunção. Nosso córpus é constituído de dados reais/espontâneos extraídos de vídeos produzidos por sujeitos surdos e publicados em blogs sinalizados. No total foram 10 vídeos analisados e 30 ocorrências do sinal motivo foram coletadas. Nossa abordagem teórica busca embasamento nos estudos sobre gramaticalização das línguas orais (HOPPER; TRAUGOTT, 2003) e das línguas de sinais (WILCOX, 2004; PFAU; STEINBACH, 2011).

Palavras-chave: Língua Brasileira de Sinais - libras. Conjunção. Gramaticalização. Orações causais.
Abstract: This paper presents the first analysis of the sign REASON in Brazilian Sign Language, offering evidence of its polysemic and multifunctional use. Our hypothesis is that the variable use of REASON represents different stages of grammaticalization (HOPPER; TRAUGOTT, 2003), where the same sign is used as a noun, adverb and conjunction. Our analysis is based on naturalistic data collected from signing blogs. Our corpus has 10 videos from where 30 cases of REASON were identified. The theoretical background for this research is studies in grammaticalization from both oral (HOPPER; TRAUGOTT, 2003) and sign languages (WILCOX, 2004; PFAU; STEINBACH, 2011).

Keywords: Brazilian Sign Language - Libras. Conjunction. Grammaticalization. Causal clauses.

\footnotetext{
1 Rodrigues. UNESP. E-mail: angelica.rodrigues@unesp.br. ORCID: https://orcid.org/0000-0003-1470-4634 2 Souza. UFSCar. E-mail: joyce.csalmeida@gmail com. ORCID: https://orcid.org/0000-0002-9055-6816
} 
- Gramaticalização do sinal "motivo" na língua brasileira de sinais: uma análise baseada no uso

\section{Introdução}

O objetivo deste trabalho é apresentar uma análise inédita do sinal Motıvo na Língua Brasileira de Sinais (libras). A partir da observação de dados espontâneos, identificamos que o sinal glosado frequentemente como "por isso" ou "por causa" apresenta usos distintos que requerem uma investigação mais aprofundada, uma vez que encontramos evidências de que a variação identificada no seu uso compreende, além de diferentes valores semânticos, a associação a categorias gramaticais distintas.

Nossa análise indica que o sinal Motivo pode ser usado como um nome (substantivo), advérbio circunstancial (PEZATTI, 2002) e como conjunção em orações causativas, explicativas e conclusivas. Nossa hipótese é que esses diferentes usos podem ser explicados tendo em vista o processo de gramaticalização (HOPPER; TRAUGOTT, 2003), em que formas lexicais passam, através do tempo, a formas gramaticais. O uso como conjunção corresponderia ao grau maior de gramaticalização, sendo, portanto, o resultado de um processo de mudança que tem como fonte um item lexical. Vasta literatura (MEILLET, 1915; HOPPER; TRAUGOTT, 2003) descreve diacronicamente a emergência de conjunções, principalmente em línguas orais, como resultado de gramaticalização. Uma vez que uma investigação diacrônica é, em princípio, como afirmam Pfau e Steinbach (2011), inviável dada a dificuldade de acesso a textos e vídeos de sincronias pretéritas que poderiam servir como registro histórico das línguas de sinais, assumimos, neste trabalho, uma perspectiva sincrônica da gramaticalização, em que os dados são interpretados num "arranjo de formas dispostas numa linha imaginária" (HOPPER; TRAUGOTT, 2003, p. 6), em cujas extremidades localizamos entidades lexicais, à esquerda, e entidades gramaticais, à direita. A coexistência, portanto, de usos lexicais e gramaticais de uma mesma palavra é usada como um recurso alternativo aos dados diacrônicos.

Para a análise dos dados, compilamos um córpus a partir de vídeos produzidos por sujeitos surdos e publicados em blogs sinalizados. Esse córpus é constituído de dez vídeos em que 30 ocorrências do sinal Motivo foram registradas. Todas as ocorrências foram anotadas através da utilização do programa ELAN.

O trabalho está organizado da seguinte forma: inicialmente apresentamos as descrições para o sinal motivo em dois dicionários da libras. Na parte 2, descrevemos nossa metodologia de coleta e análise dos dados. Nas partes 3, 4 e 5, apresentamos um resumo dos pressupostos teóricos que orientam nossa pesquisa, a gramaticalização, discussões sobre orações causais, explicativas e conclusivas, e descrições sobre as orações adverbiais, respectivamente. Na parte 6, discutimos os resultados de nossas análises. Finalmente, expomos nossas conclusões e indicamos as referências bibliográficas. 


\section{O sinal Motivo em dicionários}

Consultamos dois dicionários da Língua Brasileira de Sinais, sendo um deles na modalidade impressa e outro on-line, o modo como o sinal Motivo é descrito, considerando a sua entrada, acepção, categoria gramatical, etc.

O dicionário impresso selecionado para compor a análise deste trabalho é intitulado Dicionário da Língua de Sinais do Brasil: a Libras em suas mãos, de autoria de Capovilla et al. (2017). Esse dicionário reúne cerca de 13 mil sinais da libras em (a) entradas lexicais individuais, ordenadas em ordem alfabética. Consultamos, também, o Dicionário da Língua Brasileira de Sinais (disponível em http://www.acessibilidadebrasil.org.br/ libras_3/), de autoria de Lira e Souza (2011). Trata-se de um dicionário on-line, cuja consulta pode ser realizada pela ordem semasiológica ou onomasiológica, ou seja, a partir de campos semânticos (assuntos) ou pela configuração de mão do sinal.

Verificamos nesses dois dicionários da libras o modo como o sinal Motıvo estava registrado e como foi descrito tendo em vista o sinal propriamente dito, acepção, categoria gramatical e exemplo de uso. Após a busca, foram localizadas quatro palavras de entrada, a saber MOTIVO, POR-CAUSA-DE, POR-ISSO e RAZÃO que correspondem ao sinal glosado neste trabalho como MOTIVo.

Em Capovilla et al. (2017), localizamos as entradas "motivo" e "por causa de", conforme a Figura 1.

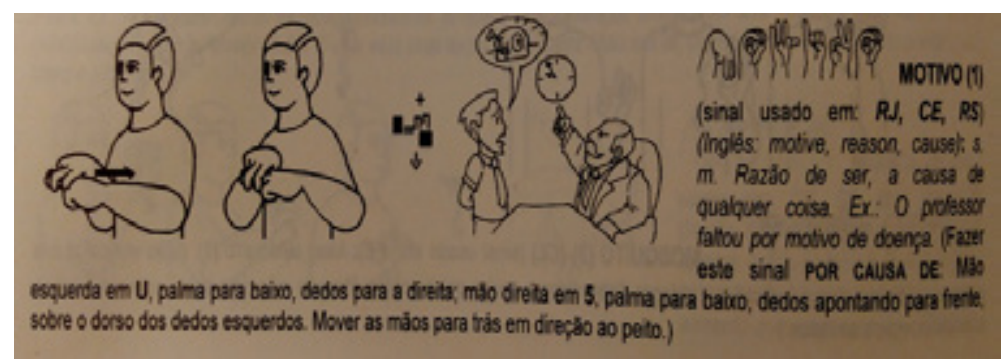

Figura 1. Sinal MOTIVo

Fonte: Capovilla et al. (2017, p. 1896)

MOTIVO é descrito como pertencente à categoria gramatical substantivo masculino (S.M) [sic], com acepção de "razão de ser, a causa de qualquer coisa, ou seja, indica causa, razão". O dicionário traz como exemplo de utilização da palavra a sentença "O professor faltou por motivo de doença". Há indicação de remissivas e uma descrição do sinal por meio dos parâmetros das línguas de sinais. No exemplo "O professor faltou por motivo de doença", fica claro que "a causa", "a razão" ou "o motivo" pelo qual o professor faltou 
- Gramaticalização do sinal "motivo" na língua brasileira de sinais: uma análise baseada no uso

foi porque estava doente, logo, justifica-se a remissiva apontada no verbete, que conduz o consulente do dicionário a consultar a palavra de entrada POR-CAUSA-DE. Embora o sinal Motivo tenha sido categorizado como sendo um substantivo, entende-se que, no exemplo apresentado no dicionário em questão, o termo empregado assume uma função de conjunção.

O sinal POR-CAUSA-DE, na Figura 2, apresenta as mesmas características microestruturais de Motıvo, diferenciando-se apenas na composição dos elementos internos do verbete. Observamos, desse modo, que para designar o sinal POR-CAUSADE, foram utilizados os mesmos parâmetros de MOtIVO. No entanto, POR-CAUSA-DE é categorizado gramaticalmente como locução prepositiva (LOC. PREP.) [sic] e sua acepção faz referência a causa, motivo, razão. O exemplo utilizado no dicionário para a referida palavra de entrada é "Ele faltou ao encontro por causa da forte gripe" e indica novamente que "a causa", "o motivo", "a razão" pelo qual o sujeito faltou ao encontro foi uma forte gripe.

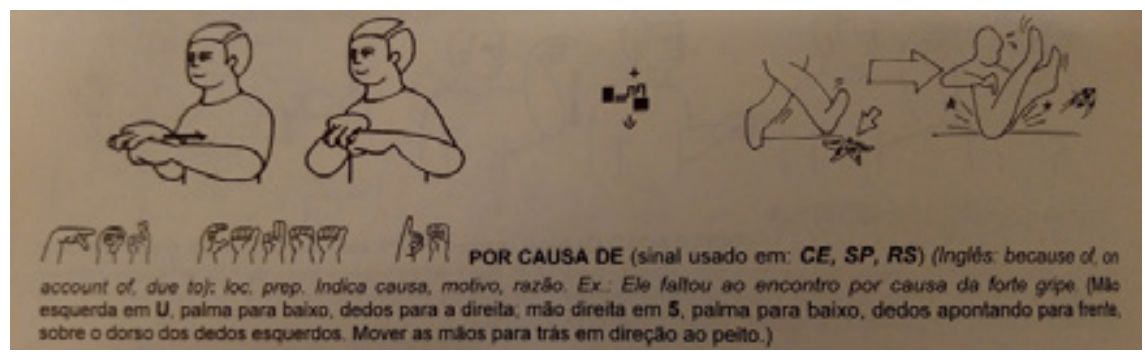

Figura 2. Sinal POR-CAUSA-DE

Fonte: Capovilla et al. (2017, p. 2228)

As categorias gramaticais distintas propostas para MOTIVO e POR-CAUSA-DE no dicionário não se baseiam em pesquisa linguística e devem ser vistas como transferência da gramática do português.

No Dicionário da Língua Brasileira de Sinais (on-line), o sinal glosado por nós como motivo é descrito de três diferentes maneiras. O sinal exibido na Figura 3 é reconhecido como pertencente à classe dos substantivos, com acepção de "causa; razão; o fator determinante", em sentenças do tipo "professor faltar motivo doença", traduzida como "O professor não foi trabalhar por motivo de doença". A Figura 4 exibe a configuração de mão (mão dominante) envolvida na produção do sinal, segundo esse dicionário: 


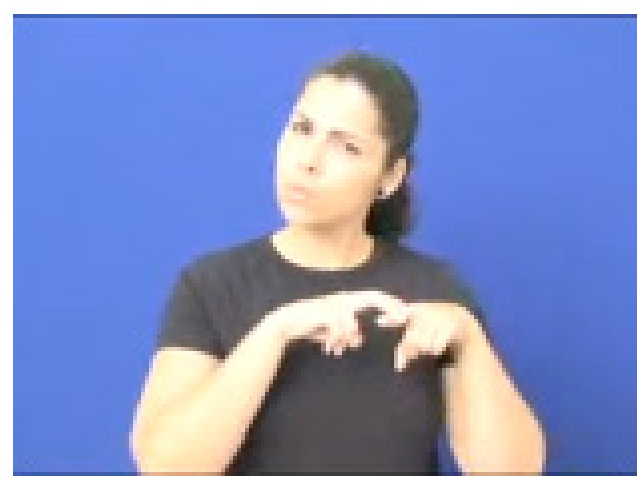

Figura 3. Sinal мотіvo

Fonte: Dicionário da Língua Brasileira de Sinais (on-line)

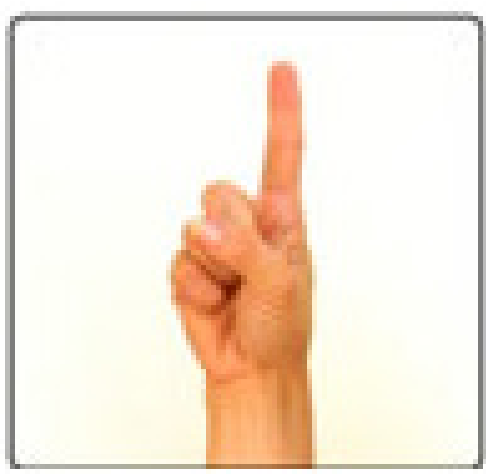

Figura 4. Configuração de mão do sinal Motıvo Fonte: Dicionário da Língua Brasileira de Sinais (on-line)

Esse mesmo dicionário descreve ainda o sinal POR-ISSO, incluído na classe das locuções/conjunções (LOC. CONJ.), com acepção de "por esse motivo; em razão de",

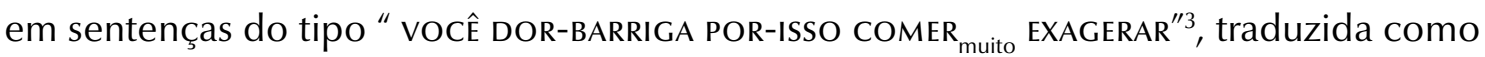
"Você comeu muito, por isso está com dor de barriga". A Figura 5 exibe o sinal glosado como POR ISSO e a Figura 6 exibe a configuração de mão (mão dominante) envolvida na produção do sinal, segundo esse dicionário:

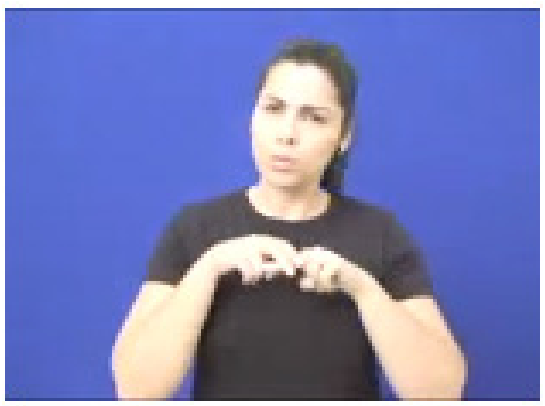

Figura 5. Sinal POR-ISSO
Fonte: Dicionário da Língua Brasileira de Sinais (on-line)

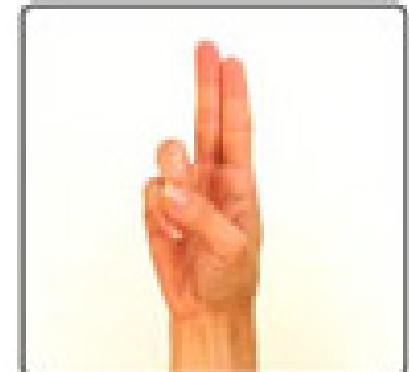

Figura 6. Configuração de mão do sinal POR-ISSO

Fonte: Dicionário da Língua Brasileira de Sinais

(on-line)

3 Notemos que o exemplo utilizado nesse caso é incompatível com o uso de "por isso" em português, uma vez que "por isso" sempre introduz um estado de coisas que é a consequência do estado de coisas expresso na primeira sentença. Por esse motivo, "por isso" só figura em sentenças pospostas à oração principal. Todavia, na glosa do exemplo fornecido pelo dicionário, POR ISSO, em libras, introduz a causa. Na tradução, a ordem das orações foi alterada. 
- Gramaticalização do sinal "motivo" na língua brasileira de sinais: uma análise baseada no uso

Esse mesmo sinal, com a mesma configuração de mão e movimento, é glosado também nesse dicionário como POR-CAUSA, pertencente à classe das locuções adverbiais (LOC.ADV.), presentena sentença “el@ trabalhar faltar POR-CAUSA ChuVA fOrte!", traduzida como "Ela faltou no trabalho por causa da chuva forte!". As Figuras 7 e 8 representam, respectivamente, o sinal e a configuração de mão correspondente a POR-CAUSA.

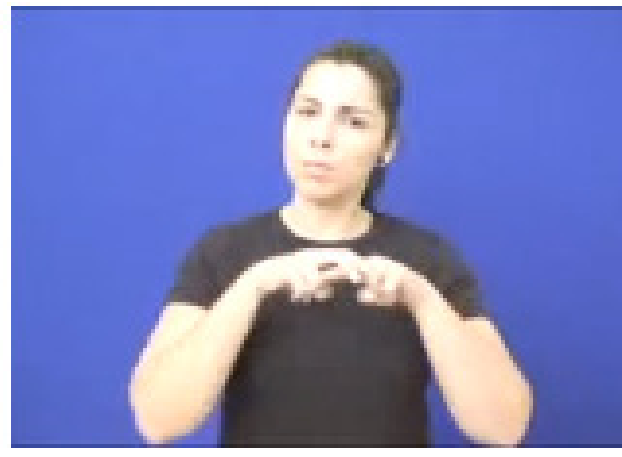

Figura 7. Sinal POR CAUSA

Fonte: Dicionário da Língua Brasileira de Sinais (on-line)

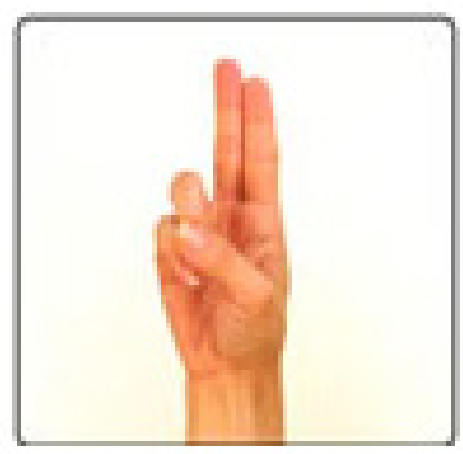

Figura 8. Configuração de mão do sinal POR CAUSA

Fonte: Dicionário da Língua Brasileira de Sinais

(on-line)

De pronto, podemos verificar uma inconsistência nos dicionários consultados em relação à descrição do sinal, que ora é descrito com a configuração de mão da Figura 4 e ora como a das Figuras 6 e 8. Ademais, as diferentes configurações de mão são associadas a acepções e classes gramaticais distintas. Outro ponto a ser observado são as inconsistências e divergências existentes quanto à classificação gramatical dos sinais encontrados.

Depreendemos, portanto, para o caso das descrições apresentadas nos dois dicionários consultados, que há uma tentativa de evitar a variação fonológica, o que leva os autores a tratar variantes como formas diferentes para um mesmo sinal.

Ao assumirmos a multifuncionalidade de MOtıvo, evitamos problemas como os observados nos dicionários consultados. Seguindo nossa proposta, apenas uma entrada seria necessária para o sinal Motıvo, que seria associado a categorias gramaticais distintas a partir do seu uso. A glosa motıvo evita ainda o problema, como observado no exemplo ilustrativo de POR-ISSO no Dicionário Online, de associação do sinal diretamente com o português. No português, encontramos várias formas que podem funcionar como conjunção causativa, explicativa e conclusiva. Em libras, as evidências são de que um mesmo sinal é usado para expressar esses três valores semânticos. Embora a glosa seja fundamental no trabalho de descrição linguística, é preciso ter cautela para que não se tome como base a língua oral para descrever uma língua de sinais. 


\section{Metodologia}

Para a análise do sinal MOTIvo, compilamos um córpus a partir de vídeos produzidos por sujeitos surdos (homens e mulheres, de idades diferentes e residentes em diferentes estados brasileiros) e publicados em blogs sinalizados do Facebook. Esse córpus é constituído de 10 vídeos em que 30 ocorrências do sinal Motıvo foram registradas. Todas as ocorrências foram anotadas através da utilização do programa ELAN.

O ELAN (HELLWIG; GEERTS, 2013 apud OUSHIRO, 2014) é um programa para anotação de arquivos de áudio e vídeo, desenvolvido pelo Instituto Max Planck de Psicolinguística e disponível em https://tla.mpi.nl/tools/tla-tools/elan/. Tendo em vista os objetivos do nosso trabalho, as trilhas de anotação criadas foram: (a) sinal mão direita; (b) sinal mão esquerda; (c) mouthing 4 e (d) tradução. A análise a partir dessas trilhas nos permite analisar a produção do próprio sinal Motıvo, a depender de sua função e valor semântico (nome, advérbio circunstancial e conjunção) e a presença de mouthing.

As ocorrências (1-3) correspondem aos três tipos de usos do sinal Motıvo em que, a partir da sua função nos enunciados, foram identificados como nome (1), advérbio circunstancial (2) e conjunção (3):

(1) Fs(dia) SEXO POR QUE? COMO CRIAR IX(este) Fs(dia) E(pausa) MOTIVo O-QUE? CUIDAR SAÚDE ${ }^{5}$ Porque criaram o dia do sexo? A razão é cuidar da saúde.

(2) PORQUE IX(nós) MORRER DV(morrer) FS(vai) PERGUNTAR \& (chamar-atenção-pessoa) IX(você) GAY OUTRO LÉSBICA FS(vai) PERGUNTAR E(impossível) MORRER ACABAR DV(enterrar) DV(cortarcabeça) DV(abrir-cérebro) IGUAL-TOdOS SEXO DENTRO IX(nós) VER VER-NÃO E(então) MOtivo IX(eu) GOSTAR-NÃO DV(rotular) TítUlo fS(homossexual) PALAVRA IX(eu) GOSTAR-NÃO Porque quando nós morrermos, alguém vai perguntar "oi, você é gay ou lésbica?". Impossível. Morreu, acabou. Se cortar a cabeça, abrir o cérebro, todo mundo é igual. Por isso eu não gosto do rótulo "homossexual". Não gosto dessa palavra.

(3) MAIS OU MENOS 20 ANO ATRÁS DV(mudar) MOTIVO IDADE IDOSO// JOVEM ÁREA IX(eles) SINAL Há mais ou menos 20 anos atrás houve uma mudança porque os jovens criaram outro sinal.

\footnotetext{
4 Mouthing é o movimento da boca baseado na pronúncia da palavra da língua oral (BAKER, 2016, p. 4). Esse movimento pode ou não ser acompanhado de som correspondente à palavra da língua oral ou à parte dela.

5 Convenções para transcrição: FS: fingerspelling; DV: verbos descritivos visuais; IX: index/referentes; E: emblema; \&: gesto. Marcadores não manuais não estão marcados nas glosas.
} 
- Gramaticalização do sinal "motivo" na língua brasileira de sinais: uma análise baseada no uso

No que concerne às normas de ética em pesquisa envolvendo a exibição de imagens, esclarecemos que, embora todos os vídeos estejam disponíveis para acesso livre na internet, não temos permissão para uso das imagens dos autores dos vídeos. Desse modo, neste trabalho utilizamos apenas as glosas dos dados analisados, preservando assim a imagem dos surdos.

\section{Gramaticalização}

No século XX, Meillet, o primeiro autor a usar o termo gramaticalização, definiu esse processo como "a atribuição de um caráter gramatical a uma palavra anteriormente considerada autônoma" (MEILLET, 1912, p. 131 apud HOPPER, 1991, p. 17). Kurylowicz (1965, p. 52 apud HEINE, 1993, p. 117), por sua vez, definiu gramaticalização como o processo pelo qual itens lexicais se tornam gramaticais ou itens gramaticais se tornam mais gramaticais através do tempo.

Segundo Hopper e Traugott (2003, p. 18), a gramaticalização é um tipo de mudança através da qual itens ou construções são usados em certos contextos linguísticos com funções gramaticais e, uma vez gramaticalizados, continuam a desenvolver novas funções gramaticais. Para esses autores, a gramaticalização é entendida como uma mudança gradual e unidirecional, que envolve deslizamento categorial e pode ser representada por um cline ou continuum. Um continuum de gramaticalização mostra que elementos com propriedades lexicais, como nome e verbo, por exemplo, podem passar, com o tempo, a exercer funções gramaticais como verbo auxiliar, preposição, afixos e conjunções:

[item de conteúdo] > [palavra gramatical] > [clítico] > afixo flexional]

(HOPPER; TRAUGOTT, 2003, p. 7)

A gramaticalização é um processo diacrônico que explica como formas gramaticais surgem e se desenvolvem nas línguas. Numa perspectiva sincrônica, a gramaticalização consiste na identificação e organização, através de um cline, de elementos que apresentam graus de gramaticalidade distintos, demonstrando os deslizamentos funcionais a que uma entidade linguística foi submetida, revelando os padrões de fluidez de uso da língua.

Pesquisas em línguas diversas (cf. HOPPER; TRAUGOTT, 2003), principalmente línguas orais, oferecem evidências de que a gramaticalização é o processo ligado à emergência de elementos gramaticais, como preposições, verbos auxiliares, artigos e conjunções etc. 
No que concerne à emergência de conjunções, tema deste trabalho, Hopper e Traugott (2003, p. 184) afirmam que seu desenvolvimento histórico é similar ao de outros itens gramaticais, tendo como fonte nomes, verbos, advérbios, pronomes, morfemas de caso, afixos derivacionais e combinações sintagmáticas (perífrases).

A emergência de conjunções foi tema do trabalho pioneiro de Meillet (1915), em que o autor questiona o fato de as conjunções frequentemente desaparecerem ou se renovarem. Para o autor, a explicação diz respeito à repetição, que levaria ao enfraquecimento expressivo do valor da conjunção (MEILLET, 1915), e sua propriedade de pertencer ao conjunto de "palavras acessórias", que tendem a ser pronunciadas mais rápido, perdendo volume fonético (MEILLET, 1915). Desse modo, as conjunções seriam afetadas por mudanças de uma perspectiva semântica e fonética.

Hopper e Traugott (2003) referem-se a casos de gramaticalização de conjunções em várias línguas. Trabalhos como Barreto (1999), Longhin-Thomazi (2011), Longhin (2016, entre outros), Rocha (2006) e Neves (2000) dão conta de casos de gramaticalização de conjunções ao longo da história do português.

No que concerne às línguas de sinais, Wilcox (2004) propõe que gestos podem se gramaticalizar nas línguas de sinais sendo incorporados inicialmente como um item lexical e adquirindo uma função gramatical com o tempo. O autor (WILCOX, 2004) remete às pesquisas de Shaffer (2000 apud WILCOX, 2004) e Janzen e Shaffer (2002 apud WILCOX, 2004) que apresentam evidências diacrônicas da gramaticalização de um morfema usado para marcar futuro a partir do morfema lexical "ir" na ASL (Língua de Sinais Americana).

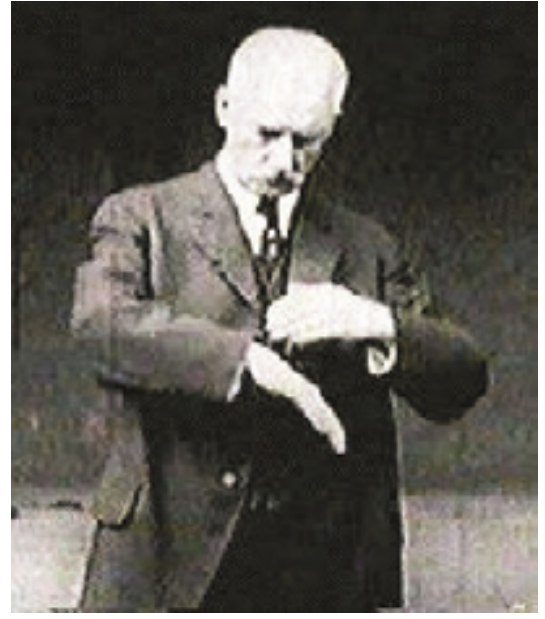

Figura 9. ASL "ir"

Fonte: Wilcox (2004)

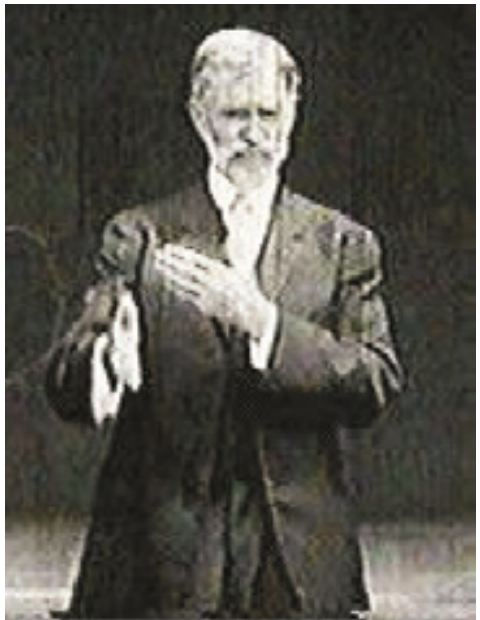

Figura 10. ASL "futuro"

Fonte: Wilcox (2004) 
- Gramaticalização do sinal "motivo" na língua brasileira de sinais: uma análise baseada no uso

Pfau e Steinbach (2011) postulam que a gramaticalização em línguas de sinais pode se dar por duas vias. Em uma delas, observamos a passagem de um item lexical a item gramatical tal como ocorre nas línguas orais. Considerando as contribuições de Wilcox (2004), os autores afirmam que a gramaticalização em línguas de sinais pode também se dar a partir de gestos que passam a exercer funções gramaticais. A gramaticalização de pronomes a partir de gestos de apontação exemplifica esse tipo de mudança nas línguas de sinais.

Xavier e Wilcox (2014) apresentam evidências para o primeiro tipo de gramaticalização em línguas de sinais ao mostrar que verbos modais em libras se gramaticalizam a partir de sinais com significados mais concretos, sofrendo, nesse processo, generalização de significado e, em alguns casos, mudança fonológica.

Schermer e Pfau (2016), por sua vez, descrevem a gramaticalização da conjunção manual REASON (1b) a partir do nome REASON (razão, motivo) (1a) na Língua de Sinais Alemã (DGS), como um exemplo dessa rota de gramaticalização.

neg

(4) a. REASON INDEX 1 UNDERSTAND.

Eu não entendo a razão

b. INDEX 1 SAD REASON POSS, GRANDMOTHER DIE.

Eu estou triste porque minha avó morreu

No que diz respeito à presença de conjunções em línguas de sinais, Tang e Lau (2012) atestam que são elementos pouco frequentes uma vez que estruturas morfossintáticas que marcam as fronteiras de sentenças, como conjunções e complementizadores, não são obrigatórias nessas línguas. Ainda assim pesquisas anteriores descrevem o uso de conjunções em línguas de sinais. Johnston e Schembri (2007) atribuem o uso de algumas conjunções na Língua de Sinais Australiana (auslan) a empréstimos do inglês, como I-F (se) e s-o (logo). Waters e Sutton-Spence (2005), por sua vez, realizam uma pesquisa quantitativa acerca das conjunções na Língua de Sinais Inglesa (BSL) e, embora reconheçam a influência do inglês falado, os autores destacam o uso intrínseco de conjunções como wh-clefts, list buoys e marcadores condicionais não-manuais. De todo modo, Waters e Sutton-Spence (2005) dão conta de 238 casos de conjunções em BSL, sendo os casos de wh-clefts, BUT (mas), MEANS (descrito como conectivo de implicação) e If (se) mais frequentes nos dados. Entre os conectivos menos frequentes, destacamos o uso de BECAUSE (porque) e so (então), como valor causal e resultativo (conclusivo), segundo Waters e Sutton-Spence (2005, p. 12-13): 
(5) CAN'T GO PUB BECAUSE MAYBE DON'T-LIKE PU3B PEOPLE não posso ir ao clube porque eles não gostam de pessoas que frequentam pubs

(6) NOTHING HIM EXPERIENCE DEAF CHILDREN HOW EXPLAIN -S- FLY SILLY-ME SAIL ENGLAND Ele não tem nenhuma experiência para explicar essas coisas para crianças surdas, então ele voou, ou navegou para a Inglaterra .

A emergência de conjunções via empréstimo está longe de ser um atributo das línguas de sinais. Mithun (1988), por exemplo, ao discutir a emergência de conjunções gramaticalizadas em línguas orais, salienta que, embora as conjunções coordenadas possam ter fontes diversas, um fator comum entre elas é que são em geral muito recentes nas línguas. Evidências encontradas em diversas línguas atestam que o bilinguismo é um fator significativo no desenvolvimento de conjunções. A exemplo disso, a autora afirma que a grande maioria das conjunções coordenadas nas línguas mexicanas são na verdade empréstimos do espanhol.

Considerando, portanto, a natureza e o uso das conjunções, em línguas orais e sinalizadas, procuramos mostrar que o estudo do desenvolvimento de conjunções em libras é promissor e pode contribuir tanto para a descrição da libras quanto para o entendimento dos processos que levam à emergência desses elementos em línguas de sinais. Nosso foco no sinal motıvo em libras permite discutir o processo de emergência de conjunções em línguas de sinais.

\section{Orações causais, explicativas e conclusivas}

Nos dados, o uso do sinal motivo está associado basicamente a valores de causaefeito/conclusão, razão pela qual revisitamos, nesta seção, alguns trabalhos em que se discutem a natureza e as propriedades das orações causais, explicativas e conclusivas. A classificação desses três tipos de orações é alvo de divergência entre gramáticos e linguistas que centram suas discussões no estatuto sintático dessas orações, ora descritas como coordenadas ora como subordinadas, e nos conectivos que explicitam o tipo de relação semântica em questão.

Entender as propriedades dessas orações que justificam tamanha controvérsia na literatura é fundamental para a análise dos nossos dados. Salientamos que, ao contrário do que se vê no português, a libras não dispõe de uma lista de conjunções causais, explicativas e conclusivas. Pelo contrário, nossa hipótese é a de que um mesmo sinal possa figurar como conjunção ou advérbio circunstancial nesses tipos de sentença em libras. 
- Gramaticalização do sinal "motivo" na língua brasileira de sinais: uma análise baseada no uso

Cunha e Cintra (2007) incluem as orações conclusivas e explicativas dentre as orações coordenadas, cuja ligação é feita por uma conjunção coordenativa conclusiva e explicativa, como em (7-9) e (10-11), respectivamente:

(7) Ouço música, logo ainda não me enterraram.

(8) Não pacteia com a ordem; é, pois, uma rebelde.

(9) Queria casar a filha, bem ao gosto dela, não punha, portanto, nenhum obstáculo ao programa de Olga.

(10) Eh, camarada, espere um pouco, que isto acaba-se já.

(11) Um pouquinho só lhe bastava no momento, pois estava com fome.

Os mesmos autores descrevem as orações causais como orações subordinadas adverbiais (CUNHA; CINTRA, 2007, p. 619). As orações causais seriam, pois, ligadas por uma conjunção subordinativa causal, como porque, como e que:

(12) Não veste com luxo, porque o tio não é rico.

Bechara (2009, p. 478) diverge dessa classificação e discute o uso de "unidades de natureza adverbial", como logo, pois, portanto, por conseguinte, por isso, então, que manifestam, entre outros, valores de conclusão, explicação e causa, e"que fazem referência anafórica ao que anteriormente se expressou". Para esse autor, portanto, o tratamento das orações explicativas e conclusivas como coordenação e das causais como subordinação é equivocado. Defende, por outro lado, que essas orações "manifestam [...] valores de dependência interna, semelhantes às orações subordinadas" (BECHARA; 2009, p. 478).

Para Castilho (2010), as orações conclusivas e explicativas enquadram-se entre as orações subordinadas (adverbiais). O autor chama a atenção para a dificuldade de sustentar a proposta tradicional de uma distinção semântica entre as causais e explicativas a partir de sentenças como (13) e (14). Na primeira, a leitura causal é favorecida pela posposição da oração causal de efeito à oração matriz (ou principal) de causa, e, na segunda, a ordem invertida leva a uma interpretação explicativa:

(13) A rua está molhada porque choveu.

(14) Choveu, porque a rua esta molhada. 
Apenas em (13) podemos aceitar uma leitura causal, uma vez que em (14) só uma leitura conclusiva é possível. Em (14), o fato de a rua estar molhada leva à conclusão de que havia chovido, todavia, a rua poderia estar molhada por outros motivos. Não há uma relação causal que se sustente nesse caso. Sendo assim, percebemos que a ordenação tem papel fundamental no efeito de sentido que se pode depreender de cada uma dessas sentenças.

Sweetser (1990) explora o uso das conjunções causais em três domínios, a saber de conteúdo, epistêmico e dos atos de fala, com base nas sentenças como em (15-17):

(15) João voltou porque ele a ama.

(16) Ele a ama, porque voltou.

(17) O que você vai fazer hoje à noite, porque tem um ótimo filme em cartaz.

Sweetser (1990, p. 81) afirma que "a conjunção causal no domínio dos atos de fala (17) indica uma explicação causal do ato de fala que está sendo produzido, enquanto no domínio epistêmico (16) a conjunção causal marcará a causa da crença ou a conclusão, e no domínio do conteúdo (15), ela marcará a causalidade do mundo real de um evento". O objetivo da autora é mostrar que a ambiguidade da conjunção causal, entre outras, está associada a seu uso nesses três domínios.

A relevância da análise proposta em Sweetser (1990) está atestada nos trabalhos de Pezzati (2002), por exemplo, para o português brasileiro. Buscando explorar as relações semânticas associadas à causa, Pezatti (2002) propõe um estudo da relação conclusiva para além da distinção coordenação/subordinação tendo como foco principal o papel dos nexos conclusivos. Procura determinar, portanto, sua função no estabelecimento da relação semântico-argumentativa e verificar o comportamento sintático-semântico desses elementos.

A autora parte, desse modo, para uma análise da oração conclusiva segundo hipótese de que, além de exprimir o nexo semântico causa-consequência, estabelece "uma relação de implicação entre a proposição antecedente e a consequente", isto é, exprime "uma relação de inferências entre proposições, em que a primeira [oração] é uma das premissas e a segunda, a conclusão" (PEZATTI, 2002, p. 191-192). É essa relação de inferência que assegura um valor conclusivo em (11), mas não em (10) acima.

Pezatti (2002, p. 192) discute ainda o estatuto categorial dos nexos conclusivos, destacando, com base em Carone (1988), que "as conjunções são geralmente expressões 
- Gramaticalização do sinal "motivo" na língua brasileira de sinais: uma análise baseada no uso

que deslizaram de um estatuto de advérbio para o de conjunção". Esse deslizamento categorial, observado no processo de gramaticalização, é reflexo da fluidez das categorias gramaticais.

Dos resultados apresentados por Pezatti (2002), destacamos aqueles relativos a por isso, uma vez que suas propriedades parecem estar mais compatíveis com alguns dos usos do sinal motıvo verificados nos nossos dados, principalmente seu valor anafórico.

A autora destaca que, com base nos seus dados, não é possível atribuir a por isso um estatuto de conjunção conclusiva prototípica. Por isso não pode ser substituído, em todos os contextos, por logo, que é, segundo ela, a conjunção conclusiva mais prototípica. Ademais, Pezatti (2002, p. 204) destaca o valor circunstancial de por isso em sentenças como (18), em que isso estabelece uma relação anafórica com "passar água fervendo sem deixar o camarão cozinhar", que atua como um esclarecimento, uma justificativa, ou mesmo causa de "o camarão ficar um pouco cor-de-rosa":

(18) então tira aquilo ali, limpa bem o camarão, passa uma água fervendo, não deixa cozinha(r) o camarão, só água fervendo no camarão, por isso que ele fica um pouco corde-rosa, não de todo, branquinho ainda, aí põe aquele refogado, mexe, apaga o fogo (PEZATTI, 2002, p. 204).

Pezatti (2002) pontua ainda que por isso pode estabelecer uma relação conclusiva entre estados-de-coisas, atuando no nível do conteúdo (SWEETSER, 1990), como em (18) acima, e uma relação de justificativa ou conclusão entre atos de fala, atuando no nível dos atos de fala (SWEETSER, 1990), como em (19):

(19) então, ele vai desejar que o aluno não fique apenas no nível de memorização, mas que, uma vez armazenada esta informação, ele utilize essa informação em outros, em outras situações, por isso nós dissemos que habili, chamamos de habilidades mentais. (PEZATTI, 2002, p. 208).

A autora destaca ainda que por isso pode operar no nível epistêmico (SWEETSER, 1990), sendo esse valor associado à relação propriamente conclusiva:

(20) existem CERtas regiões onde há determinados frutos OUtras regiões... com OUtros frutos... então eles tinham que acompanhar este movimento também:: e por isso eram nômades. (PEZATTI, 2002, p. 207).

Marques e Pezatti (2015), por sua vez, destacam a controvérsia entre alguns gramáticos e linguistas quanto à natureza semântica das orações conclusivas. Kury (1993), 
por exemplo, afirma que a oração conclusiva exprime conclusão ou consequência lógica em relação ao estado de coisas descrito na primeira oração. Ducrot (2009 apud MARQUES; PEZATTI, 2015, p. 30), por seu turno, advoga a favor de um encadeamento argumentativo, em que pesa a necessidade de sustentação de certa argumentação. Em (21), segundo Ducrot, o uso de portanto tem a intenção de persuadir o interlocutor mais do que estabelecer uma relação lógica conclusiva:

(21) A estação é longe, portanto tomemos um táxi. (MARQUES; PEZATTI, 2015, p. 31).

Segundo Neves, Braga e Dall'Aglio-Hattnher (2008, p. 946-947), "a construção causal pode ser caracterizada como a junção entre um evento-causa e um eventoconsequência ou evento-efeito", implicando "uma sequência temporal entre os eventos, à qual se soma a ideia de que o segundo evento é previsível a partir do primeiro (ou porque tem nele a sua razão), ou porque há entre eles uma sucessão regular". As autoras defendem que o valor semântico de "causa" abrange "causa real, razão, motivo, justificativa ou explicação" e "'efeito' abrange consequência real, resultado, conclusão" (NEVES; BRAGA; DALL'AGLIO-HATTNHER, 2008, p. 952).

Salientam também que a ordem marcada das orações causais é a posposição e que essa ordenação leva em consideração a organização discursiva e o domínio da conexão. Seguem Sweetser (1990) e dividem as orações causais do português em três tipos: de conteúdo, epistêmicas e de atos de fala. As causais de conteúdo estabelecem uma relação causal entre estados de coisas que estão relacionados por uma causalidade em um mundo qualquer e pressupõem uma sequência temporal de fatos (NEVES; BRAGA; DALL'AGLIO-HATTNHER, 2008, p. 948), como em (22):

(22) Então eles pegavam os pássaros que não podiam voar... porque estavam com as penas grudadas de petróleo

As orações causais que atuam no domínio epistêmico estabelecem uma relação entre "uma conclusão ou crença, por um lado, e as suas 'causas' ou 'motivações', por outro lado" (NEVES; BRAGA; DALL'AGLIO-HATTNHER, 2008, p. 949), como em (23):

(23) agora nesse mês, como a UPC não aumentou e como diminuiu o número de UPCs... o que vai acontecer é que eu vou pagar um pouquinho menos

As orações causais no domínio dos atos de fala associam um ato de fala a uma "sentença que dá a 'causa' daquele ato de fala - e, por isso, traz uma 'explicação' -" (NEVES; BRAGA; DALL'AGLIO-HATTNHER, 2008, p. 949), como em (24): 
- Gramaticalização do sinal "motivo" na língua brasileira de sinais: uma análise baseada no uso

(24) [agora dias que não tem aula ele pergunta e a resposta é negativa aí então ele diz para a irmã...] "levanta que hoje não tem aula podemos brincar" aí levan::tam

A relação causal envolve matizes semânticos e pragmáticos diversos e pode ser expressa em construções sintáticas distintas no português, considerando o conjunto de conjunções que são usadas nessas sentenças e a ordenação das sentenças.

Tendo em vista a proposta de Sweetser (1990), acerca da atuação das conjunções em três domínios, a saber de conteúdo, epistêmico e dos atos de fala, podemos concluir também que as relações de causa, explicação e conclusão operam em domínios distintos, ainda que envolvam os mesmos tipos de conectivos.

Desse modo, Marques e Pezatti (2015, p. 24) defendem que "a relação conclusiva [...] ocorre no domínio epistêmico", uma vez que "expressa a ideia de que o julgamento da verdade da primeira afirmação leva à crença relatada na segunda". No nível epistêmico, "[n]ão se pode perceber uma lógica inerente às duas afirmações, mas uma relação em que uma dada situação leva a uma determinada conclusão". As orações explicativas, por sua vez, pertencem ao domínio dos atos de fala, como já demonstrado em Marques e Pezatti (2015) e Neves, Braga e Dall'Aglio-Hattnher (2008). Já as orações causais operam no domínio do conteúdo, uma vez que expressa uma causa real, verificada em qualquer mundo, em que fica nítida uma sequência temporal de estados de coisas.

Com base no trabalho de Dancygier (1998) sobre as condicionais, podemos prever ainda que as causais atuem no que a autora chama de domínio metatextual. Se encaixam aqui as sentenças em que os conectores funcionam como advérbios circunstancias, como descrito em Pezatti (2002). Nessas sentenças, Pezatti (2002) descreve que o conector por isso tem uma função anafórica. Para Dancygier (1998), sentenças no nível metatextual retomam os enunciados anteriores para introduzir um comentário.

Podemos concluir que a distinção entre esses valores semânticos está associada ao tipo de domínio em que cada tipo de oração opera. Nossa proposta é descrever o uso do sinal Motıvo, envolvido em sentenças causais, explicativas e conclusivas a partir das propostas de Sweetser (1990) e Dancygier (1998), corroboradas por Neves, Braga e Dall'Aglio-Hattnher (2008) e Marques e Pezatti (2015), identificando os quatro domínios de atuação desse conectivo na libras. 


\section{Orações adverbiais em línguas de sinais}

Na seção anterior, apresentamos um resumo da vasta discussão sobre os valores semânticos associados à causalidade e conclusão. Além disso, mostramos que há uma divergência entre gramáticos e linguistas acerca da natureza dessas relações com respeito ao estatuto sintático das orações que veiculam esses valores de causa, explicação e conclusão. Essa discussão recai sobre os parâmetros identificados para distinguir coordenação e subordinação. Tratados numa perspectiva dicotômica, coordenação e subordinação são descritos com base nos parâmetros dependência e independência nas gramáticas tradicionais. Autores como Hopper e Traugott (2003) e Lehmann (1988), por outro lado, defendem uma abordagem diferente por reconhecerem que as orações compostas podem ser mais bem entendidas tendo em vista um continuum de predicação complexa que liga sentenças com graus de integração mais ou menos fortes e compreende três tipos principais de vinculação de sentenças, a saber parataxe, hipotaxe e subordinação. Nessa proposta, são levados em conta parâmetros como dependência e encaixamento.

No que concerne às línguas de sinais, não encontramos na literatura parâmetros para distinguir coordenação e subordinação, embora autores como Johnston e Schembri (2007), Tang e Lau (2012) e Pfau (2016) descrevam casos de orações coordenadas e subordinadas, destacando, contudo, a dificuldade dessa distinção em línguas de sinais.

Pfau (2016), por exemplo, discute casos de orações adverbiais temporais, causais e finais, e condicionais em várias línguas de sinais. Uma vez que trataremos, neste trabalho, de casos de orações causais, destacaremos a descrição apenas desse tipo de oração.

Pfau (2016) chama atenção para o fato de que as sentenças com a conjunção manual causal na Língua de Sinais Holandesa (NGT) são similares às sentenças do inglês e outras línguas orais, como em (25):

(25) INDEX1 ANGRY [BeCAUSE INDEX3a ALWAYS LATE COME]. Eu estou bravo porque ela se atrasou

Pfau e Steinbach (2011) propõem que o sinal REASON na Língua de Sinais Alemã (DGS) pode ser usado como conjunção causal como resultado de um processo de gramaticalização. Os autores argumentam que essa conjunção se gramaticalizou a partir do nome REASON e introduz nessa língua orações adverbiais causais como em (26): 
- Gramaticalização do sinal "motivo" na língua brasileira de sinais: uma análise baseada no uso

(26) INDEX1 SAD REASON POSS1 DOG DIE Eu estou triste porque meu cachorro morreu

Para a libras, não encontramos descrição do uso de orações causais, explicativas e conclusivas. Nosso objetivo é, desse modo, apresentar uma análise do uso do sinal MOTIVo em sentenças desse tipo, buscando apresentar pela primeira vez uma descrição de orações adverbiais em libras.

\section{Análise}

Apresentaremos, nesta seção, os resultados das nossas análises baseadas em 30 ocorrências do sinal Motıvo identificadas em 10 vídeos. Esses resultados advêm de uma análise qualitativa, dado o pequeno número de ocorrências, em que foram analisados fatores como mouthing, domínio cognitivo (de conteúdo, epistêmico ou dos atos de fala) e tipo de oração (causal, explicativa ou conclusiva).

Para tratar da multifuncionalidade do sinal мотıvo, discutiremos inicialmente, a seguir, nossa proposta de que esses diferentes usos, interpretados como nome, advérbio e conjunção correspondem a diferentes graus de gramaticalização. Na subseção seguinte, analisaremos a atuação desse sinal em domínios semânticos distintos, como propõem Sweetser (1990) e Dancygier (1998).

\section{Gramaticalização da conjunção Moтıvo}

Nossos dados favorecem a interpretação de que a conjunção мотıvo é fruto de um processo de gramaticalização em que um item lexical passa a item gramatical, como propõem Hopper e Traugott (2003). Trata-se, portanto, do mesmo processo verificável em línguas orais e, como atestam Pfau e Steinbach (2011), também na DGS.

O sinal Motivo é usado como um nome dentro de um sintagma nominal em (27) e para conectar dois estados de coisas, em que uma relação causal é estabelecida, como (28):

(27) FS(dia) SEXO POR QUE? COMO CRIAR IX(este) fs(dia) E(pausa) MOtIVO O-QUE? CUIDAR SAÚde Porque criaram o dia do sexo? (pausa) A razão é cuidar da saúde. 
(28) IX(eU) USAR MÉDiCO1 Motivo ÁREA JOVEM MÉDico1// 20 ANOS ATRÁS MÉDICO1 IDADE IDOSO IX MÉDICO2

Eu uso o sinal "médico7" porque eu sou jovem, o sinal usado há 20 anos atrás era "médico2"

Nossa interpretação para a diferença na categorização de Motıvo leva em conta questões prosódicas. Em (27), há uma longa pausa depois do sinal SEXO e o retorno da mão do sinalizante para a posição de repouso, o que pode marcar o início de uma nova sentença. Em (28), por outro lado, não há pausa entre as duas sentenças, que parecem estar mais vinculadas sintática e semanticamente. Considerando esses dois usos do sinal Motıvo, defendemos que o uso mais gramatical, como conjunção, é resultado de um processo de gramaticalização a partir de um uso mais lexical. Sustentam essa hipótese os trabalhos clássicos de gramaticalização, como Hopper e Traugott (2003), em que está proposto que as mudanças em gramaticalização seguem uma trajetória unidirecional tal como:

menos gramatical > mais gramatical

O princípio básico pressuposto na hipótese da unidirecionalidade é, segundo Hopper e Traugott (2003), a assunção de que há uma relação entre os estágios A e B, de modo que $A$ ocorre antes de $B$, mas não o contrário. Desse modo, a interpretação de que o uso do sinal motıvo como uma conjunção causal é posterior ao seu uso como elemento lexical, apesar de não poder ser atestado diacronicamente, encontra respaldo nos inúmeros casos atestados em outras línguas, a partir dos quais foi possível formular o princípio da unidirecionalidade da mudança em gramaticalização.

O sinal PORQUe (Figura 10) também pode ser usado em contextos semelhantes, como em (29), embora seja muito mais comum em contextos de pergunta (com expressão facial de interrogação).

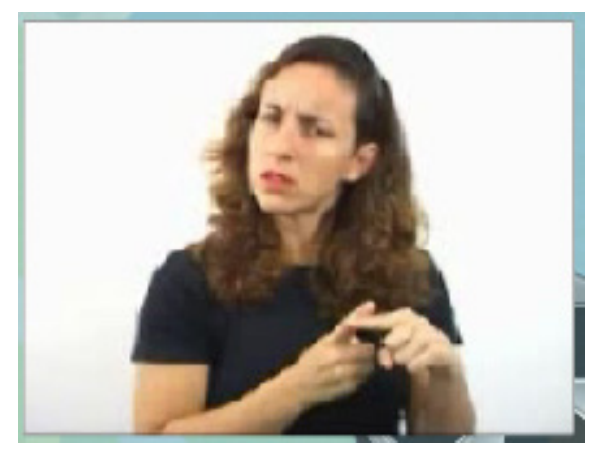

Figura 10: PORQUE

Fonte: Mini dicionário ilustrado de Libras 
- Gramaticalização do sinal "motivo" na língua brasileira de sinais: uma análise baseada no uso

Em (29), temos um caso em que a conjunção manual PORQUE é usada para ligar dois estados-de-coisas, ou duas sentenças causais:

(29) XXX DIFERENTE PORQUE DEPENDE FS(orgasmo) ORGASMO

As pessoas sentem prazer em regiões diferentes porque depende do orgasmo.

Em (30), todavia, temos a ocorrência dos dois sinais em sequência, o que podemos entender como uma evidência da emergência da conjunção Motıvo em contextos de causa:

(30) BARCO3 INDEX3 CL-VELA-DO-BARCO DEPENDER VENTO VENTILAR M̃̃o-DIREITA $_{\text {OU VENTILAR }}$ MÃO-ESQUERDA OU VENTILAR EM-FRETE $_{\text {POSSÍVEL LIVRE CONSEGUIR NAVEGAR PORQUE }}$ EXP.INTERRoGatVA MOTIVO INDEX3 CL-VELA- DO-BARCO

Tradução 1: A posição da vela do Barco depende da direção do vento. Isso permite que ele consiga navegar. Por quê? O motivo é da vela do barco.

Tradução 2: A posição da vela do Barco depende da direção do vento. O barco consegue navegar, porque tem vela.

Nessa ocorrência, PORQUE, associado a uma expressão facial de interrogação, é usado no que parece ser uma pergunta retórica. Essa estratégia é muito usada nas línguas de sinais, como atesta Pfau (2016, p. 157) para a NGT em (24):

(31) INDEX3 $_{3}$ SAD WHY, INDEX $3_{2}$ CAT DIE.

Ele está triste porque seu gato morreu

Por que ele está triste, é(porque) seu gato morreu

O que difere as traduções de (30) é que na primeira o sinal Motıvo aparece num contexto em que tanto pode ser interpretado como nome ou como uma conjunção (no caso, coocorrendo com PORQUE). As duas interpretações apontam, portanto, para uma ambiguidade estrutural do sinal Motıvo, o que é um traço comum entre os itens em processo de gramaticalização.

A natureza gradual da gramaticalização compreende estágios no processo que leva um item lexical a adquirir funções gramaticais. Em estágios intermediários, podem emergir usos que evidenciam o caráter não-discreto das categorias gramaticais. Em (32) abaixo, por exemplo, o sinal MOTIvo apresenta uma função intermediária entre nome e conjunção, na medida em que parece exercer uma função de advérbio circunstancial, como proposto por Pezatti (2002) para alguns usos de por isso, com valor anafórico. O motivo ou razão pela qual o falante aconselha os interlocutores a serem mais cautelosos 
quanto a acusações contra os intérpretes está descrito nas sentenças anteriores. Logo, o sinal Motivo retoma tudo o que foi dito anteriormente e introduz uma justificativa para que os interlocutores evitem difamar ou caluniar os intérpretes:

(32) USAR ACUSAR INTÉRPRETE TRADUTOR? E(negação) EVITAR USAR TAMBÉM DISCRIMINAR E (negação) SE IX(você) PODER PRECISAR FUtUro INTÉRPRETE-TRADUTOR IX(você) PRECISAR IX(el@) DEPENDER Ix(você) PEDIR Ix(el@s) Ix(eu) QUERER INTÉRPRETE E(esperar) DESCULPAR Ix(el@) DISCRIMINAR IX(eu)\&(INDIGNAÇÃo) IX(el@) PRECISAR IX(eL@) INTÉRPRETE- IX(eu) ENTENDER-NADA MOTIVO MARCAR DV(pesSOa) CUIDADO IX(vOcê) PRECISAR PENSAR ANTES REFLETIR RESPONDER

Acusar o tradutor intérprete? Não não, deve-se evitar isso e também discriminá-los. Você pode vir a precisar de um tradutor intérprete futuramente, e dependendo você pede pra el@sque quer um intérprete e aí, el@s podem dizer: espera aí, desculpa, você me discriminou e agora você precisa de intérprete? Não estou entendendo nada. Por isso, tome cuidado para não ficar marcado. Pense antes, reflita para responder.

Análises de dados como (30) e (32) são fundamentais para estudos de gramaticalização sobre línguas para as quais não é possível fazer um estudo diacrônico. $O$ cline abaixo, desse modo, parte de uma perspectiva sincrônica, sustentada pelos dados.

MOTIVO $_{\text {NOME }}>$ MOTIVO $_{\text {ADV }}>$ MOTIVO $_{\text {CONJUNÇÃO }}$

Segundo Hopper e Traugott (2003, p.6), sincronicamente, um cline, representa um arranjo de formas numa linha imaginária, em que, provavelmente, formas lexicais e formas gramaticais ocupam posições opostas. Nossa proposta de cline para acomodar os diferentes usos do sinal motivo leva em conta, portanto, as evidências sincrônicas que sustentam nossa hipótese de que esses diferentes usos correspondem a diferentes graus da gramaticalização.

\section{Valores semânticos e domínios associados ao sinal Motıvo}

Com base nas propostas de Sweetser (1990) e Dancygier (1998), descreveremos os usos do sinal Motivo em quatro domínios: de conteúdo, epistêmico, dos atos de fala e metatextual.

Dos 30 dados coletados, Motivo está associado ao domínio do conteúdo em 13 ocorrências, ao domínio epistêmico em 4, ao domínio dos atos de fala em 5 e ao domínio metatextual em 3. Em 2 ocorrências o sinal foi usado como nome e em outras 3 ocorrências é usado para indicar finalidade. 
- Gramaticalização do sinal "motivo" na língua brasileira de sinais: uma análise baseada no uso

Embora fuja do escopo deste artigo explorar o uso de motivo em contextos de finalidade, cabe destacar que, nessas ocorrências, Motıvo é usado não com valor de causa, mas de objetivo/finalidade, como em (33). Pfau (2016) observa situação semelhante na DGS (Língua de Sinais Alemã), em que o sinal REASON (motivo) é usado tanto para introduzir uma oração causal quanto final.

(33) X(eu) VIR SÓ E(passar informação) IX(vocês) SABER PORQUE DIA 6 MÊS SETEMBRO E(pergunta) FS(dia) SEXo COMO CRIAR SER MOtIVO CUIDAR SAÚdE

Eu vim aqui avisar vocês porque dia 6 de setembro é o dia do sexo, que foi criado para orientar as pessoas no cuidado com a saúde.

MOTIVo atua no domínio do conteúdo em sentenças como (34) e (35), em que podemos observar uma relação de causa e consequência entre dois estados de coisas.

Em (34), observamos uma relação causal no domínio do conteúdo, em que há uma relação temporal entre um evento de causa e um evento de efeito/consequência: o informante relata que no passado ele não sinalizava, mas como passou a ter contato com outros surdos, houve uma mudança e ele aprendeu libras. O evento causa é o contato com outros surdos e o evento consequência é o aprendizado da libras. Notem que há uma relação temporal icônica entre os eventos causa e consequência. Qualquer alteração nessa ordem alteraria o sentido do enunciado. Todavia essa iconicidade não se reflete na ordenação das sentenças, já que em libras a relação causal é expressa em sentenças cuja ordenação dos eventos é não icônica, isto é, a sentença de consequência é anteposta à sentença de causa.

(34) IX(eu) PASSADO CRESCER IX(eu) LS NADA LS NADA LS NADA IX(eu) CRESCER

DV(transformação)LS XXX IX MOTIVO DV(pessoas-influenciar-eu) IX(eu) PASSADO IX(eu) PARTICIPAR CONVIVER ÁREA APROPRIAR DESENVOLVER MUDAR

Antigamente eu não sinalizava nada. Quando eu cresci houve uma mudança porque eu recebi influência de outras pessoas com quem eu convivi no passado.

Em sentenças como (35) e (36), motıvo atua no domínio epistêmico porque a sentença introduzida por esse sinal expressa uma crença mais do que um estado de coisas.

Em (35) e (36) temos uma relação de conclusão determinada por uma crença expressa na sentença introduzida por Motıvo. Em (35), o informante discute o tabu relativo à sexualidade. Segundo ele, esse tabu existe por causa do machismo. A relação 
entre a existência de um tabu referente à orientação sexual e o machismo é estabelecida no nível epistêmico, uma vez que é válida apenas pela própria opinião ou conhecimento de mundo do informante. Não há um evento causal que provoque uma consequência como em (34).

(35) IX FS(tabu) IX MOTIVO IX(eu) MACHISMO INFLUENCIAR EVOLUIR IX(eu) HOMEM Isso é um tabu porque tem influência do machismo.

(36) é produzido pelo mesmo informante ainda numa discussão sobre o tema da sexualidade. Ele se refere às discussões ${ }^{6}$ sobre orientação sexual e conclui que essas discussões começaram por causa de uma novela. Assim como em (30), a relação entre as discussões sobre sexualidade e novela estão estabelecidas no nível epistêmico, pois tratase de uma crença que o próprio informante explicita.

(36) XXX COMEÇAR MOTIVO IX(el@) NOVELA FS(novela) TER Isso começou por causa da novela.

As ocorrências de motivo em (37) e (38) são representativas da sua atuação no domínio dos atos de fala. Em (37) e (38), o sinal motivo é usado para introduzir uma sentença que na verdade expressa um ato de fala. Em (37), a razão pela qual "se usa" ou "se diz" a palavra "homossexual" está explicitada na sentença anterior. Em (38), o sinal motivo introduz um ato de fala que é justificado pelo conteúdo da sentença anterior.

(37) FS(homo) SINGNIFICAR MESMO FS(sexo) DV(palavra-duas-juntar) MOtIvo IX PALAVRA FS(ok) "homo" significa mesmo, com sexo, forma uma palavra por isso usa a palavra "homossexual".

(38) CERTO Fs(é) FS(fim) 10 PROLIbras \&(indignação) SÉtIMO E(então) Motivo AVISAR ATÉ 2015 FS(fim) MOTIVO DECRETO CRIAR FS(é) 2005

O correto seria finalizar no décimo Prolibras, mas foi até o sétimo, então, por isso divulgaram que terminaria até 2015, por causa do Decreto que foi criado em 2005.

A ocorrência (39) é representativa nos nossos dados do uso de Motivo como advérbio circunstancial, que atua no nível metatextual. O sinal Mотıvo, nessa ocorrência, retoma todos os enunciados precedentes para introduzir uma conclusão que, assim como as causais do domínio epistêmico, está baseada numa crença ou opinião do próprio

6 Não podemos compreender o sinal exato que o informante usa, mas, no contexto, o tema são as discussões que as pessoas passaram a ter sobre orientação sexual. 
- Gramaticalização do sinal "motivo" na língua brasileira de sinais: uma análise baseada no uso

informante. A diferença entre (39) e (37-38) é que somente na primeira há uma retomada anafórica do conteúdo dos enunciados anteriores. Assim, a razão pela qual o informante não gosta da palavra "homossexual" está expressa e/ou subentendida nos enunciados precedentes.

(39) PORQUE IX(nós) MORRER DV(morrer) FS(vai) PERGUNTAR \& (chamar-atenção-pessoa) IX(você) GAY OUTRO LÉSBICA FS(vai) PERGUNTAR E(impossível) MORRER ACABAR DV(enterrar) DV(cortarcabeça) DV(abrir-cérebro) IGUAL-TOdOS SEXO DENTRO IX(nós) VER VER-NÃO E(então) MOTIVo ix(eu) GOSTAR-NÃO DV(rotular) TítUlo fs(homossexual) PALAVRA IX(eu) GOSTAR-NÃO

Porque quando nós morrermos, alguém vai perguntar "oi, você é gay ou lésbica?". Impossível. Morreu, acabou. Se cortar a cabeça, abrir o cérebro, todo mundo é igual. Por isso eu não gosto do rótulo "homossexual". Não gosto dessa palavra.

\section{Outras propriedades das orações com Motıvo}

Todas as orações com Motıvo analisadas mantêm a ordem canônica das orações causais, que é a posposição. Paiva (1999) assevera que a ordem não-marcada, ou preferencial, das sentenças causais introduzidas por porque, em português, é a posposição. Diferentemente do português oral, na libras, a anteposição nesses casos seria agramatical. Todavia, a ordenação das orações causais na libras ainda permanece um aspecto pouco explorado.

Em nossa análise, observamos também o uso de mouthing associado à produção do sinal Motıvo. Os resultados, como ilustra a Tabela 1, não nos permitem fazer conclusões muito precisas acerca da relação entre o tipo de mouthing e o valor semântico das orações em que o sinal motıvo é usado. Consideramos que pesquisas com um maior número de dados são necessárias para uma análise mais acurada desse fenômeno.

Tabela 1. Distribuição dos mouthings

\begin{tabular}{l|l|l|l|l}
\hline \multicolumn{1}{c|}{$\begin{array}{c}\text { Domínios } \\
\text { Mouthing }\end{array}$} & Conteúdo & Epistêmico & Metatextual & Atos de fala \\
\hline por causa & 4 & 3 & - & 1 \\
\hline por isso & - & 1 & 2 & 2 \\
\hline porque & 1 & - & - & - \\
\hline sem/ininteligível & 8 & - & 1 & 2 \\
\hline Total & 13 & 4 & 3 & 5 \\
\hline
\end{tabular}

Fonte: Elaboração própria 
Com base na análise dos dados que constituem nosso córpus, pudemos apresentar uma descrição dos usos do sinal Motıvo em sentenças que veiculam sentidos de causa, explicação e conclusão associados aos domínios de conteúdo, epistêmico, dos atos de fala e metatextual. Não observamos nenhuma propriedade nas sentenças analisadas que justificasse uma distinção no tipo de vinculação sintática entre as orações envolvidas. A diferença entre as ocorrências analisadas reside primordialmente em propriedades semânticas, que nos permitiram propor três usos distintos, com implicação na categorização do mesmo sinal como nome, advérbio circunstancial e conjunção, com atuação em quatro domínios cognitivos correspondente a sua atuação nos níveis do conteúdo, epistêmico, dos atos de fala e metatextual.

\section{Conclusão}

Neste trabalho, apresentamos um estudo preliminar dos usos do sinal Motivo na libras. Nossa análise considerou dados reais produzidos por surdos sinalizantes e publicados em vídeos na internet para mostrar aspectos relacionados à categorização e aos valores semânticos desse sinal.

Num primeiro momento, discutimos o estatuto gramatical de Mотіvо, considerando as evidências de que pode ser usado como um item lexical, como substantivo, quanto como um item gramatical, com função de conjunção. Observamos ainda que MOtıvo pode ser usado também em alguns contextos com função de advérbio circunstancial, com valor anafórico. Sendo assim, postulamos a hipótese de que os diferentes usos de мотіvo, que coexistem sincronicamente, podem ser entendidos como reflexo do deslizamento categorial ao qual esse item foi submetido. O cline NOME>ADVÉRBIO>CONJUNÇÃO explicaria, portanto, a trajetória de mudança desse elemento, compatível com gramaticalização, em que observamos que um elemento lexical passou a desempenhar funções gramaticais. O uso como advérbio circunstancial explicita o caráter gradual da mudança por gramaticalização e os efeitos do deslizamento categorial.

Num segundo momento, nos debruçamos sobre os valores semânticos associados ao sinal Mотıvo, considerando seu uso em sentenças que veiculam valores semânticos distintos. Nossos dados revelaram que Motıvo ocorre em sentenças com valores causais, explicativas e conclusivas, que atuam em domínios de conteúdo, epistêmico, dos atos de fala e metatextual, segundo as propostas de Sweetser (1990) e Dancygier (1998).

Embora as línguas orais, pelo menos as línguas indo-europeias, apresentem uma lista de conjunções causais, os estudos de Pezatti (2002), Marques e Pezatti (2015) e Neves, Braga e Dall'Aglio-Hattnher (2008) mostram que uma mesma conjunção, no caso 
- Gramaticalização do sinal "motivo" na língua brasileira de sinais: uma análise baseada no uso

do português, a conjunção porque, pode ser usada em sentenças nos quatro domínios. Destacamos, desse modo, que a libras, nesse aspecto, não se difere do português, ou seja, nossos dados deixam evidente que o sinal motıvo articula sentenças com sentidos relacionados à causa, explicação e conclusão.

Durante a coleta de dados, observamos também que o sinal PORQUE, usado em sentenças interrogativas, parece poder funcionar como conjunção causal. Futuramente é nosso objetivo analisar esses usos de PORQUE para que possamos contrastar os resultados e aprofundar os estudos das relações de causa em libras. Aspectos relacionados ao uso de marcadores não-manuais também deverão ser explorados futuramente, para que possamos apresentar uma descrição mais completa das sentenças causais em libras. Salientamos também a necessidade de uma análise das orações de causa justapostas, considerando que esse modo de vinculação sintática é mais produtivo nas línguas de sinais (TANG; LAU, 2012). São necessárias, portanto, novas pesquisas sobre o tema, com um córpus ampliado para que novas análises possam servir de base para afirmações mais contundentes acerca das propriedades das orações causais em libras. De todo modo, nossos resultados são inéditos no que diz respeito ao tema e, por esse motivo, podem contribuir para os estudos descritivos de libras.

\section{Agradecimentos}

A pesquisa de pós-doutoramento que levou aos resultados apresentados aqui recebeu financiamento da Fundação de Amparo à Pesquisa do Estado de São Paulo (FAPESP - Processo 2015/23541-2).

\section{Referências}

BAKER, A. Sign languages as natural languages. In: BAKER, A.; BOGAERDE, B. van den; PFAU, R.; SCHERMER, T. (ed.). The Linguistics of Sign Languages: An Introduction. Amsterdam: Benjamins, 2016. p. 1-24.

BARRETO, T. M. M. Gramaticalização das conjunções na história do português. 1999. v. I e II. Tese (Doutorado em Letras e Linguística) - Instituto de Letras, Universidade Federal da Bahia, Salvador, 1999.

BECHARA, E. Moderna gramática portuguesa. São Paulo: Nacional, 2009. 
CAPOVILLA, F. C.; RAPHAEL, W. D.; TEMOTEO, J. G.; MARTINS, A. C. Dicionário da Língua de Sinais do Brasil: a libras em suas mãos. v. 3: Sinais de P a Z. São Paulo: EDUSP, 2017.

CASTILHO, A. T. de. Gramática do Português Brasileiro. São Paulo: Contexto, 2010.

CUNHA, C.; CINTRA, L. F. L. Nova gramática do Português contemporâneo. Rio de Janeiro: Nova Fronteira, 2007 [1985].

DANCYGIER, B. Conditionals and predication (Cambridge Studies in Linguistics). Cambridge: Cambridge University Press, 1998.

Dicionário de LIBRAS do INES (http://www.acessibilidadebrasil.org.br/libras/).

DUCROT, O. Argumentação retórica e argumentação linguística. Letras de Hoje, Porto Alegre, v. 44, n. 1, p. 20-25, jan./mar. 2009.

HEINE, B. Auxiliaries. Cognitive Forces and Grammaticalization. New York: Oxford University Press, 1993.

HOPPER, P. J. On Some Principles of Grammaticalization. In: TRAUGOTT, E.; HEINE, B. Approaches to Grammaticalization. v. I. Amsterdam: John Benjamins, 1991. p. 17-35.

HOPPER, P. J.; TRAUGOTT, E. C. Grammaticalization. Cambridge: Cambridge University Press, 2003 [1993].

JOHNSTON, T.; SCHEMBRI, A. Australian Sign Language. An Introduction to Sign Language Linguistics. Cambridge: Cambridge University Press, 2007.

KURY, A. da G. Novas lições de análise sintática. 6. ed. São Paulo: Ática, 1993 [1985].

KURYLOWICZ, J. The evolution of grammatical categories. Diogenes 51. p. 55-77. Reprint 1975, Esquisses linguistiques II. München: W. Fink (International Library of General Linguistics, 37), p. 38-54, 1965.

LIRA, G. A.; SOUZA, T. A. F. Dicionário digital da língua brasileira de sinais. v. 3. Rio de Janeiro: Instituto Nacional de Educação de Surdos - INES, 2011. Disponível em: http:// www.acessibilidadebrasil.org.br/libras_3/.Acesso em: 09 dez. 2019. 
- Gramaticalização do sinal "motivo" na língua brasileira de sinais: uma análise baseada no uso

LONGHIN, S. R. Regularidade em mudança semântica: um estudo de caso no domínio da junção. LABORHISTÓRICO, v. 2, p. 130-148, 2016.

LONGHIN-THOMAZI, S. R. Flutuação e gramaticalização no paradigma dos juntores em português: forma, significado e história. Filologia e Lingüística Portuguesa, v. 13, p. 147166, 2011.

MARQUES, N. B. N.; PEZATTI, E. G. A relação conclusiva na língua portuguesa: funções resumo, conclusão e consequência. São Paulo: Cultura Acadêmica, 2015.

MEILLET, A. L'évolution des formes grammaticales. Scientia. Revista di Scienza 12, v. 26, n. 6, p. 130-148, 1912. (Reprint: Meillet 1921).

MEILLET, A. Le renouvellement des conjonctions. In: École pratique des hautes études, Section des sciences historiques et philologiques. Annuaire 1915-1916. 1915. p. 9-28.

Mini dicionário ilustrado de LIBRAS. Disponível em: http://www.faders.rs.gov.br/ uploads/Dicionario_Libras_CAS_FADERS1.pdf. Acesso em: 22 jan. 219.

MITHUN, M. The grammaticization of coordination. In: HAIMAN, J.; THOMPSON, S. (ed.). Clause Combining in Grammar and Discourse. Amsterdam: Benjamins, 1988. p. 33-59.

NEVES, M. H. de M. Gramática de usos do português. São Paulo: UNESP, 2000.

NEVES, M. H. M.; BRAGA, M. L.; DALL'AGLIO-HATTNHER, M. As construções hipotáticas. In: NEVES, M. H. M.; BRAGA, M. L.; DALL'AGLIO-HATTNHER, M. (org.). Gramática do Português Culto Falado no Brasil. Classes de Palavras e Processos de Construção. v. II. Campinas: Editora da UNICAMP, 2009.

PAIVA, M. C. A. A ordem não marcada das cláusulas 'porque'. Série Encontros Descrição do Português Abordagens Funcionalistas, UNESP, Araraquara, v. 1, p. 263-280, 1999.

PEZATTI, E. G. As construções conclusivas em português. In: ABAURRE, M. B. M; RODRIGUES, A. C. S. (org.). Gramática do Português Falado. v. VIII. Campinas: Editora da UNICAMP, 2002. 
ROCHA, A. P. A. Gramaticalização das conjunções adversativas em português: em busca da motivação conceptual do processo. 2006. Tese (Doutorado em Letras) - Pontifícia Universidade Católica, Rio de Janeiro, 2006.

SCHERMER, T.; PFAU, R. Language contact and change. In: BAKER, A.; BOGAERDE, B. van den; PFAU, R.; SCHERMER, T. (ed.). The Linguistics of Sign Languages: An Introduction. Amsterdam: Benjamins, 2016. p. 299-324.

PFAU, R. Syntax: complex sentences. In: BAKER, A.; BOGAERDE, B. van den; PFAU, R.; SCHERMER, T. (ed.). The Linguistics of Sign Languages: An Introduction. Amsterdam: Benjamins, 2016. p. 149-172.

PFAU, R.; STEINBACH, M. Grammaticalization in sign languages. In: NARROG, H.; HEINE, B. (ed.). The Oxford handbook of grammaticalization. Oxford: Oxford University Press, 2011. p. 683-695.

SWEETSER, E. From Etymology to Pragmatics. Metaphorical and Cultural Aspects of Semantic Structures. Cambridge: Cambridge University Press, 1990.

TANG, G.; LAU, P. Coordination and subordination. In: PFAU, R.; STEINBACH, M.; WOLL, B. (ed.). Sign Language: An International Handbook. Berlin: Mouton De Gruyter, 2012. p. 340-365.

WATERS, D.; SUTTON-SPENCE, R. Connectives in British Sign Language. Deaf Worlds, v. 21, n. 3, p. 1-29, 2005.

WILCOX, S. Gesture and language; cross-linguistic and historical data from signed languages. Gesture, v. 4, p. 43-73, 2004.

XAVIER, A. N.; WILCOX, S. Necessity and possibility modals in Brazilian Sign Language (LIBRAS). Linguistic Typology, v. 18, n. 3, p. 449-488, 2014. 
- Gramaticalização do sinal "motivo" na língua brasileira de sinais: uma análise baseada no uso

COMO CITAR ESTE ARTIGO: RODRIGUES, Angélica, e SOUZA, Joyce Cristina. Gramaticalização do sinal "motivo" na língua brasileira de sinais: uma análise baseada no uso. Revista do GEL, v. 16, n. 1, p. 53-82, 2019. Disponível em: https:/ / revistadogel.gel.org.br/

DOI: http://dx.doi.org/10.21165/gel.v16i1.2435

Submetido em: 24/02/2019 | Aceito em: 13/11/2019. 